\title{
A geospatial model for the optimization grazing management in semi-arid rangeland of Iran
}

\begin{abstract}
Extensive livestock grazing even in unsuitable land has increasingly grown in most parts of semi-arid rangeland. Therefore, it is of paramount importance to identify suitable land for livestock grazing for optimum utilization while causing minimum impact to the environment. This paper adapted the schematic model based on the concepts presented by the Food and Agriculture Organization of suitability analysis for optimal grazing management in semi-arid rangeland in Iran. Factors affecting extensive grazing were determined and incorporated into the model. Semi-arid rangeland with variable such as climate and other agents were examined for common types of animal grazing and the advantages and limitations were elicited. Many ecosystem components affect land suitability for livestock grazing but due to time and funding restrictions, the most important and feasible elements were investigated. Within the model parameters, three submodels including water accessibility source, forage production, and erosion sensitivity were considered. Suitable areas at four levels of suitability were determined using geographic information systems. This suitability modeling approach was adopted due to its simplicity and the minimal time required for transforming and analyzing datasets. The most important reducing factors in model suitability were found to be: (a) land use and vegetation cover (in relation to soil erosion sensitivity), (b) the amount of the available forage in comparison with the total production, and (c) the existence of less palatability plants among the pasture plant species (forage production suitability). The results of the study would be beneficial to rangeland managers in devising measures more wisely to cope with the limitations and enhance the health and productivity of the rangelands.
\end{abstract}

Keyword: Extensive grazing; GIS; Iran; Modeling; Range suitability; Semi-arid rangeland 